\title{
Estudo comparativo do Padrão de Descrição de Informação e MARC 21 em partitura de pianola
}

\author{
Milene Rosa de Almeida Moura ${ }^{I}$ \\ Luzia Sigoli Fernandes Costa ${ }^{I I}$
}

\begin{abstract}
IUniversidade Federal de São Carlos, Programa de Pós-Graduação em Ciência, Tecnologia e Sociedade, São Carlos, SP, Brasil. Doutoranda do Programa de Pós-Graduação em Ciência, Tecnologia e Sociedade da Universidade Federal de São Carlos (UFSCar). Bibliotecária-Documentalista do Instituto Federal de São Paulo.

${ }^{I I}$ Docente do Programa de Pós-Graduação em Ciência, Tecnologia e Sociedade da Universidade Federal de São Carlos (UFSCar). Doutora em Ciência da Informação pela Universidade Estadual Paulista (UNESP - Marília).
\end{abstract}

http://dx.doi.org/10.1590/1981-5344/2979

A variedade de bens materiais situados nas fazendas históricas paulistas suscitou a preocupação em preservar e compartilhar com a sociedade importantes referências históricas da formação econômica brasileira. A preocupação com a preservação destes ambientes culminou no desenvolvimento de projetos de políticas públicas, tendo como produtos finais as ferramentas para a organização e registro dos bens patrimoniais: sistema Memória Virtual Rural, para o cadastro dos itens e Padrão de Descrição de Informação, que permite que sejam catalogados todo o patrimônio situado nas fazendas, dada a sua variedade de campos. No presente trabalho realizou-se um estudo comparativo com o Padrão de Descrição de Informação e o padrão MARC 21 com aplicação em partitura de pianola, para avaliar a capacidade de descrição do primeiro. Partindo de uma pesquisa exploratória, criou-se o referencial teórico sobre catalogação. Do ponto de vista de sua natureza, trata-se de uma pesquisa aplicada. A abordagem apresenta-se como qualitativa, visto que seus resultados são obtidos por meio de análises não numéricas. Por fim, concluiu-se 
que o Padrão de Descrição de Informação possui um alto grau de completude, necessitando de pequenas intervenções a fim de permitir uma descrição mais completa deste tipo de material.

Palavras-chave: Fazenda histórica paulista. Patrimônio cultural. Catalogação. MARC 21. Partituras.

\section{Comparative study of Information Description Standard and MARC 21 in score of pianola}

The variety of material goods located in São Paulo historical farms increased the concern about preserving and sharing the major society historical references of the Brazilian economic formation. Regarding for the preservation of the environments culminated a public policy projects development, in order to obtain as a result the tools for the organization and recording of the capital assets: Rural Virtual Memory system (RVM), for the registration of the items and Information Description Standard (IDS), which allows to be catalogued, in order to get all the heritage located on these farms listed, because of its variety of fields. In the present project, a comparative study of the Information Description Standard (IDS) and the MARC 21 Standard for application in score of pianola, allowed to evaluate the capability description of the first one. Starting from an exploratory research, we created the theoretical framework about cataloging. From the point of view of its nature, it is an applied research. The approach was presented as qualitative, since their results are not obtained by numerical analysis. Finally, it was found that the IDS have a high degree of completeness, but it requires a little assistance to enable a more complete description of this kind of material.

Keywords: São Paulo historical farm. Cultural heritage. Cataloging. MARC 21. Scores.

Recebido em 20.10.2016 Aceito em 27.08.2018

\section{Introdução}


Representantes dos "anos de ouro" da economia agrária, as fazendas históricas paulistas abrigam um rico e vasto acervo de bens patrimoniais, constituído por documentos, construções, objetos e a cultura, como as lendas e costumes que fazem parte do imaginário popular.

A fim de valorizar esse rico universo de bens materiais e imateriais foram desenvolvidos projetos de políticas públicas, financiados pela Fundação de Amparo à Pesquisa do Estado de São Paulo (FAPESP): "Memória Virtual de São Carlos" (2004-2008), "Patrimônio Cultural Rural Paulista: Espaço Privilegiado para Pesquisa, Educação e Turismo" (20082012) e "Critérios e metodologias para realização de inventário do patrimônio cultural rural paulista" (2012-2014).

$\mathrm{Na}$ primeira fase do projeto foi desenvolvido um sistema web para a gestão de acervos das fazendas, visando integrar os acervos municipal, regional, estadual e nacional (MEMÓRIA..., 2004-2008; NAKAGAWA; CRISTIANINI; MORAES, 2006). O projeto seguinte teve como objetivo disponibilizar instrumentos e metodologias, como o Padrão de Descrição de Informação (PDI), para a gestão, a conservação e a difusão destes bens patrimoniais entre os proprietários das fazendas e as instâncias públicas das áreas culturais, educacionais e do turismo. No projeto vigente entre 2012 a 2014 desenvolveu-se inventários das fazendas históricas paulistas da região de São Carlos, o aprimoramento do PDI e do sistema de base de dados Memória Virtual Rural. Atualmente, o projeto continua vigente, porém sem fomento externo.

O presente trabalho apresenta sucintamente os resultados obtidos em pesquisa ${ }^{1}$, cujo intuito foi realizar um estudo comparativo entre os campos do PDI e os campos do formato Machine Readable Cataloging (MARC 21), através da catalogação de partitura de pianola, possibilitando avaliar o PDI segundo a capacidade de representação descritiva, propondo melhorias na estrutura descritiva do PDI caso necessário.

Metodologicamente desenvolveu-se pesquisa exploratória com levantamento bibliográfico, resultando no referencial teórico sobre catalogação. A natureza da pesquisa é aplicada, pois através da catalogação de partitura utilizando o PDI e o MARC 21 foi possível estabelecer uma comparação entre ambos e verificar a capacidade representacional do primeiro. A abordagem do problema é qualitativa, uma vez que os resultados obtidos não podem ser expressados numericamente.

A inserção do patrimônio histórico rural no ambiente das tecnologias de informação e comunicação (TIC) cumpre o papel de disponibilizar à sociedade informações sobre os bens pertencentes a este espaço. Este tipo de divulgação traz vantagens para os gestores das fazendas, pela oportunidade de divulgar a propriedade e estimular a visitação in loco, considerando que a renda de muitas dessas fazendas decorre do turismo

1 ALMEIDA, M. R. de Padrão de Descrição de Informação: avaliação da capacidade representacional de bens materiais. 2014. Dissertação (Mestrado em Ciência, Tecnologia e Sociedade) - Universidade Federal de São Carlos, São Carlos, 2014. 
rural; e para os pesquisadores, que tem a oportunidade de analisar o ambiente rural sob perspectivas teóricas e experimentais.

\section{Catalogação e MARC 21: revisão de literatura}

Desde os períodos remotos, o homem preocupou-se em registrar o conhecimento de sua vivência, e consequentemente surgiram as primeiras normativas de descrição física. Na Antiguidade as tábulas de argila eram utilizadas para o registro da informação; entre os séculos XV a XVII o desenvolvimento da tipografia e da imprensa causaram grande impacto no acesso à informação pela sociedade; nos dias atuais o acesso à informação se dá principalmente pela Internet, devido à velocidade.

A preocupação com o aumento de informação registrada acarretou na busca de métodos que sistematizassem as informações de modo que sua recuperação se desse de modo rápido e ágil, chegando à organização da informação, ou controle bibliográfico, constituída por operações distintas, sendo uma delas a catalogação.

A catalogação faz parte de uma cadeia de procedimentos denominada processo documental, que se constitui de sucessivas operações seguindo uma lógica, criando um processo de circulação da informação que tende a estabelecer um vínculo entre os documentos e os usuários, permitindo sua difusão. A catalogação apresenta-se como uma forma de apresentar ao usuário diferentes alternativas na escolha de um item, ou seja, permitir ao usuário localizar um determinado documento como também outros que tenham ligação com o primeiro, ampliando seu universo de escolhas (MEY; SILVEIRA, 2009).

Com o intenso crescimento tecnológico ocorrido após a Segunda Guerra Mundial, uma variedade de recursos informacionais surgiu, modificando significativamente os serviços de processamento de informação, incluído a automatização do processo de catalogação.

Em 1965 surge o formato MARC, da Library of Congress. O objetivo principal em sua concepção foi permitir a comunicação de descrições bibliográficas por um formato cuja leitura pudesse ser realizada por computadores, de modo que todos os registros fossem formatados para atender qualquer necessidade, em qualquer lugar do mundo, por qualquer centro de informação ou usuário (BARBOSA; EDUVIRGES, 2010, p. 4). Os elementos do formato MARC foram baseados na estrutura descritiva dos códigos de catalogação, e são preenchidos conforme as regras estabelecidas nestes, garantindo assim maior consistência na representação por ele gerada (FERREIRA, 2002).

De acordo com Alves (2010, p. 34):

[...] o código de catalogação AACR uniformizou os catálogos e registros bibliográficos, e o formato MARC efetivou a automação desses registros, tornando o processo de catalogação, o processo de intercâmbio e exportação de dados, mais consistente e ágil. 
No Brasil, o formato MARC data de 1972, implementado por Alice Príncipe Barbosa na Fundação Getúlio Vargas (FGV) e denominado projeto Catalogação Legível por Computador (CALCO). Em 1976 o projeto CALCO passa a se chamar Bibliodata/CALCO e no final dos anos 1990 Rede Bibliodata, utilizando o formato USMARC e atualmente MARC 21, que utiliza padrões como a International Standard Bibliographic Description (ISBD), Anglo-American Cataloguing Rules (AACR2), Library of Congress Subject Headings ( $L C S H$ ) na descrição de seu conteúdo.

Os campos do MARC 21 são os seguintes:

OXX Informação de controle, números e códigos

1XX Entradas principais

2XX Títulos, edição, imprenta

3XX Descrição física

$4 X X$ Série

$5 X X$ Notas

6XX Entradas de assunto

7XX Entradas secundárias de assunto ou série

8XX Entradas secundárias de série (outras formas de autoridades)

9XX Reservado para decisões locais

O PDI, por sua vez, permite o registro patrimonial dos bens situados nas fazendas históricas paulistas, seja ele material (bens bibliográficos, arquivísticos, arqueológicos, imagéticos, arquitetônicos etc.) ou imaterial (receitas, lendas, costumes, depoimentos etc.). Através da identificação, caracterização e análise, independente do suporte em que se encontra, dada a amplitude desses bens, visa-se a criação de práticas de inventários das propriedades rurais.

Assim como o MARC 21 é inserido em sistemas informáticos, comerciais ou livres, o PDI é disponibilizado no sistema web livre chamado Memória Virtual Rural, de modo que as informações sobre qualquer bem, de qualquer fazenda, sejam disponibilizadas de modo integrado.

O PDI foi delineado a partir de preceitos teóricos e metodológicos das áreas da Ciência da Informação e da Ciência da Computação na descrição dos bens patrimoniais. Sua primeira versão realizou o mapeamento dos atributos e requisitos de cada tipo de acervo, estabelecendo relações que permitissem apoiar a modelagem do sistema Memória Virtual Rural (MVR), subdividindo estes atributos em 10 grupos. A segunda e atual versão subdividiu os atributos em 13 grupos, com 60 campos e subcampos de descrição, conforme a tipologia do bem (COSTA; SCARPELINE; NAKAGAWA, 2010). No Quadro 1 são expostos os 13 grupos do PDI, seguidos de explanação sobre a função de cada grupo:

Quadro 1 - Grupos do Padrão de Descrição de Informação

\begin{tabular}{c|l|l}
\hline Grupo & \multicolumn{1}{|c|}{ Conteúdo do campo } & \multicolumn{1}{c}{ Atributos do bem patrimonial } \\
\hline \hline G1 & Identificação da fazenda & $\begin{array}{l}\text { Dados sobre a propriedade, o proprietário e o gestor, endereço e coordenadas } \\
\text { geográficas, o tipo de propriedade, a proteção e legislação incidente, imagens e } \\
\text { demais informações sobre o contexto histórico cultural em que se insere a } \\
\text { propriedade. }\end{array}$ \\
\hline $\mathbf{G 2}$ & $\begin{array}{l}\text { Informações gerais do } \\
\text { bem patrimonial }\end{array}$ & $\begin{array}{l}\text { Dados sobre a natureza e tipologia do bem, o registro, o título, o nível de } \\
\text { descrição (arquitetônico, arquivístico, bibliográfico, bem móvel integrado, } \\
\text { iconográfico e natural), localização física com as devidas coordenadas do bem. }\end{array}$ \\
\hline
\end{tabular}




\begin{tabular}{|c|c|c|}
\hline G3 & Autoria & $\begin{array}{l}\text { Dados relacionados com a variedade de tipos de autoria ou responsabilidades } \\
\text { atribuídas à criação do bem descrito. }\end{array}$ \\
\hline G4 & Cadastro de autoria & $\begin{array}{l}\text { Dados complementares ao Grupo } 3 \text { como nome, pseudônimo, função ou } \\
\text { atividade e período de existência. }\end{array}$ \\
\hline G5 & Produção & $\begin{array}{l}\text { Dados sobre o local, ano, versões, edições e responsabilidades concernentes à } \\
\text { produção do bem patrimonial. }\end{array}$ \\
\hline G6 & Descrição & $\begin{array}{l}\text { Dados de conteúdo, estilo, resumo, características físicas, dimensões e } \\
\text { volumetria, análise estilística, iconográfica e o contexto espacial e temporal do } \\
\text { bem descrito e meio de acesso. }\end{array}$ \\
\hline G7 & Audiovisual & Dados e materiais produzidos pela pesquisa realizada durante o inventário. \\
\hline G8 & $\begin{array}{l}\text { Diagnóstico e } \\
\text { intervenção }\end{array}$ & $\begin{array}{l}\text { Dados sobre o estado de conservação do bem, as intervenções realizadas com } \\
\text { os seus respectivos responsáveis. }\end{array}$ \\
\hline G9 & $\begin{array}{l}\text { Disponibilidade, uso e } \\
\text { proteção }\end{array}$ & $\begin{array}{l}\text { Dados sobre a situação de disponibilidade, condição de acesso, uso, } \\
\text { reprodução, aproveitamento e proteção do bem patrimonial descrito. }\end{array}$ \\
\hline G10 & Histórico da procedência & $\begin{array}{l}\text { Dados sobre os tipos de transação, valor venal, data de aquisição do bem } \\
\text { patrimonial. }\end{array}$ \\
\hline G11 & Assunto e descritores & $\begin{array}{l}\text { Palavras-chave. Termo livre de linguagem natural e termos controlados, } \\
\text { retirados de um vocabulário pré-definido, que traduzem o conteúdo temático } \\
\text { do bem patrimonial. }\end{array}$ \\
\hline G12 & Fonte de informação & $\begin{array}{l}\text { Dados sobre as fontes de informação utilizadas na pesquisa histórica do bem } \\
\text { patrimonial, independente da sua natureza e tipo de bem patrimonial. }\end{array}$ \\
\hline G13 & $\begin{array}{l}\text { Responsável pela } \\
\text { pesquisa }\end{array}$ & $\begin{array}{l}\text { Nome do responsável pela pesquisa histórica, data da coleta de dados e } \\
\text { anotações complementares feitas pelo pesquisador. }\end{array}$ \\
\hline
\end{tabular}

Fonte: COSTA; SCARPELINE; NAKAGAWA (2010, p. 8).

A criação do PDI e a análise e identificação de novos atributos suscitou a necessidade de se conhecer códigos, normas e roteiros que pudessem fornecer subsídios no estabelecimento de parâmetros para a coleta de dados, a descrição e a geração de conteúdos. Para Nakagawa, Costa e Scarpeline (2010, p. 21), os códigos, normas e roteiros capazes de fornecer os requisitos necessários para uma descrição bastante abrangente e exaustiva são:

[...] o Código de Catalogação Anglo-Americano (AACR2), para descrição de documento bibliográfico, a Norma Geral Internacional de Descrição Arquivística ISAD (G), para documentos de arquivo do International Council on Archives (ICA, 2000), o Dublin Core e a EAD (Encoded Archival Description), [...] o sistema de descrição usado pelo Instituto do Patrimônio Histórico e Artístico Nacional (IPHAN), [...] bem como um sistema usado pela Prefeitura Municipal de Uberlândia (MG). Em relação aos bens iconográficos, particularmente a descrição de imagens fotográficas, o PDI foi comparado com os padrões usados pelo Centro de Memória da Unicamp (CMU) e pelo Sistema de Apoio à Comunicação Integrada (SACI), desenvolvido pela UFSCar.

Deste modo, observou-se a necessidade de ampliar o estudo relacionado ao formato de registro MARC 21 para aprofundamento dos aspectos de identificação, armazenamento e intercâmbio de dados.

\section{Padrão de descrição de informação e MARC 21: análise comparativa}

A coleta de dados ocorreu no acervo da Fazenda Santa Maria do Monjolinho, localizada no município de São Carlos - SP. A propriedade impressiona pela arquitetura de suas construções, refletindo a riqueza sucedida do cultivo do café em seus tempos áureos. Adquirida por José 
Inácio de Camargo em 1850, a fazenda foi comprada em 1904 por Candido de Souza Campos e Zuleika Malta, com todos os pertences que estavam em seu interior; atualmente a quinta geração de seus descendentes é responsável pela guarda do patrimônio.

Nesta pesquisa, realizou-se a catalogação de partituras de pianola, instrumento da família do piano, mas que possui um dispositivo que executa automaticamente a música, por meio de pedais e alavancas manuais. Uma curiosidade deste instrumento é que ele era utilizado como uma forma de lograr os pretendentes das jovens solteiras das tradicionais famílias da época, que por não terem o dom para a música, recorriam à tecnologia da pianola para fingir que sabiam tocar piano.

O preenchimento do PDI se deu a partir do Grupo 2 (Informações Gerais do Bem Patrimonial), pois as informações do Grupo 1 dizem respeito à propriedade rural, não pertinentes ao propósito do estudo, uma vez que as amostras foram retiradas de um só local. No caso de música escrita (partitura), a fonte principal de informação é a página de rosto, pode-se ainda utilizar outra fonte de informação pertencente ao material que forneça maiores informações sobre o item a ser descrito. Como o vocabulário controlado do projeto encontra-se em desenvolvimento, atribuiu-se a linguagem natural no campo de assunto do PDI e o vocabulário controlado Bibliodata nos campos de assunto (6XX) do MARC 21.

São apresentadas a seguir imagens referentes à partitura de pianola selecionada para catalogação, realizada tanto com o PDI quanto com o MARC 21, e em sequência iniciam-se as exposições das análises, seguidas de explanações sobre as comparações efetuadas.

\section{Figura 1 - Partitura de pianola}

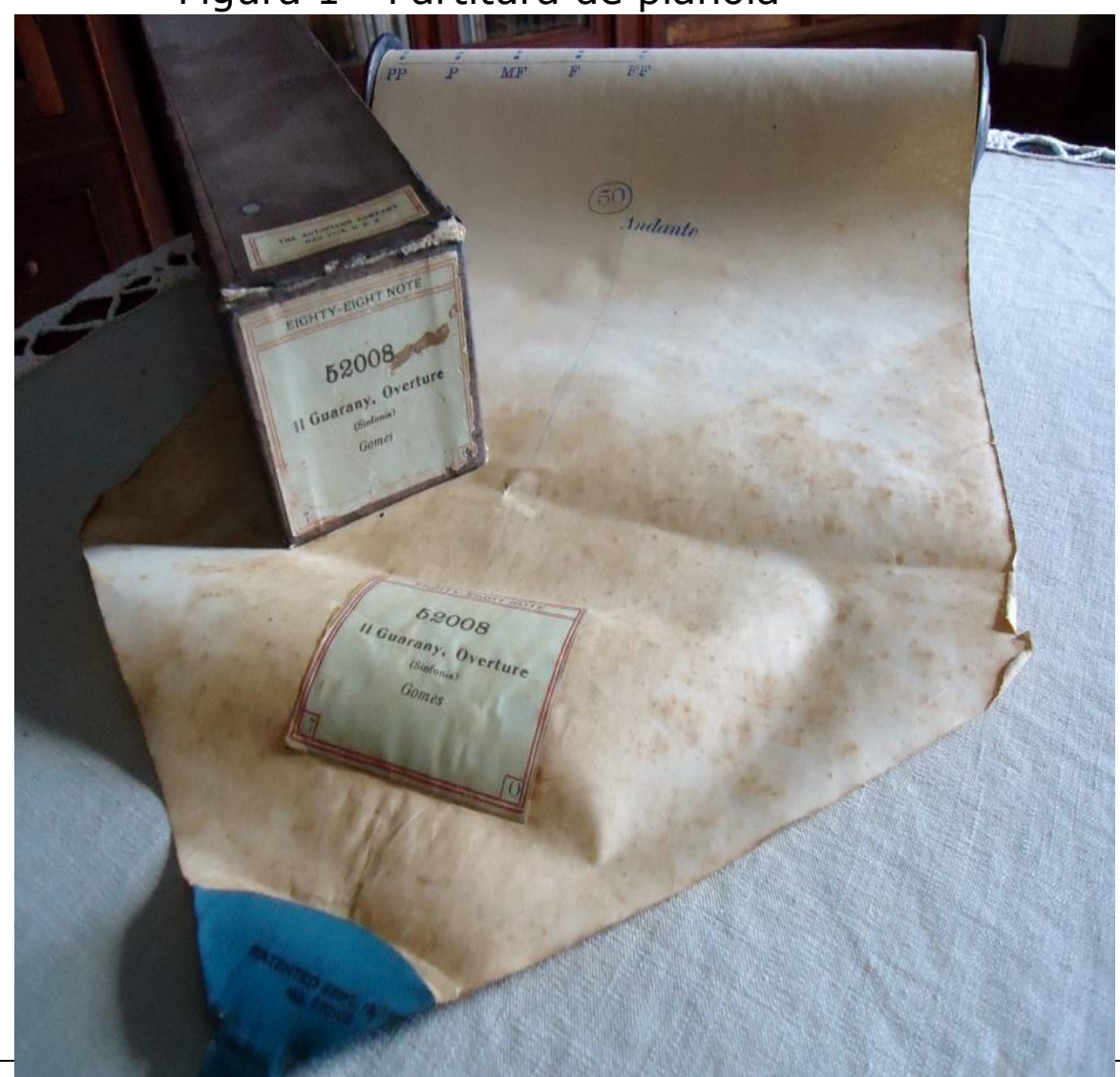

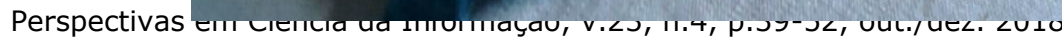


Fonte: Autoras.

Figura 2 - Partitura de pianola

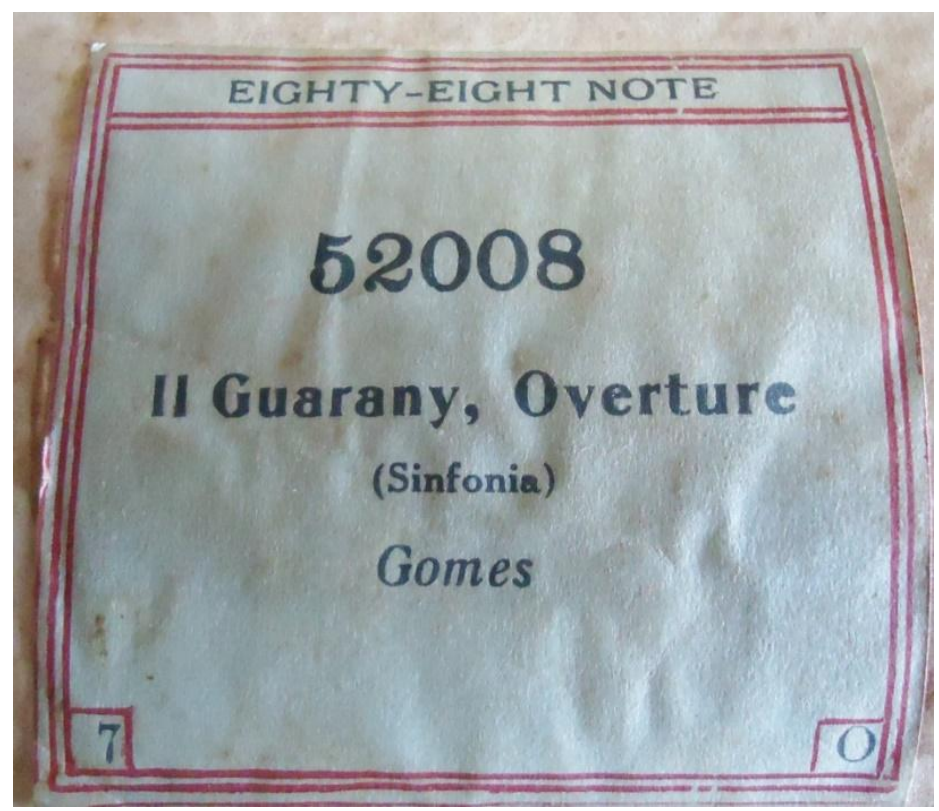

Fonte: Autoras.

Quadro 2 - Comparação do grupo 2 do PDI

\begin{tabular}{|c|c|c|c|}
\hline \multicolumn{2}{|c|}{ PADRÃO DE DESCRIÇÃO DE INFORMAÇÃOO } & \multicolumn{2}{|r|}{ MARC 21} \\
\hline Grupo/ Item / Nome & Descrição & Campo & Representação \\
\hline $\begin{array}{l}\text { G2 2.0 Disponibilização para acesso } \\
\text { externo }\end{array}$ & Não & - & - \\
\hline G2 2.1 Natureza do bem patrimonial & Material & - & - \\
\hline $\begin{array}{l}\text { G2 2.1.2 Natureza do bem } \\
\text { material }\end{array}$ & Música & - & - \\
\hline G2 2.2 Tipo do bem patrimonial & Partitura & Formato & FMT UM \\
\hline G2 2.3 Número de registro & FSMJ-M-E4 & Número de controle & 001 MVR 000000204 \\
\hline G2 2.4 Título & Il Guarany: overture & Título principal & 24513 \$a Il Guarani \\
\hline G2 2.4.1 Tipo do título & Principal & & $\begin{array}{l}\text { \$h [música] : } \\
\text { \$b overture (sinfonia) / } \\
\text { \$c Gomes. - }\end{array}$ \\
\hline $\begin{array}{l}\text { G2 } 2.6 \text { Localização física } \\
\text { especifica }\end{array}$ & $\begin{array}{l}\text { Biblioteca Dr. } \\
\text { Ernesto de Souza } \\
\text { Campos, Estante } 4 .\end{array}$ & Localização & $\begin{array}{c}85241 \text { \$a Fazenda Santa Maria do } \\
\text { Monjolinho } \\
\text { \$b Biblioteca Dr. Ernesto de } \\
\text { Souza Campos } \\
\text { \$c Estante 4. }\end{array}$ \\
\hline
\end{tabular}

Fonte: Dados da pesquisa.

A análise do grupo 2 do PDI (Quadro 2), ao ser comparado com os campos do MARC 21, evidenciou a necessidade de pequenas adequações. Os campos 2.0 e 2.1 foram considerados satisfatórios, e ao contrário do formato MARC 21, o PDI não contempla este tipo de material. Assim, sugere-se o acréscimo de categoria dedicada à música no item 2.1.2 (Natureza do Bem Material), seja acrescido de uma categoria dedicada à música. 
O campo 2.2 (Tipo do bem patrimonial) utiliza termos livres em seu preenchimento, o que pode gerar falhas ao se recuperar a informação; deste modo sugere-se a padronização da terminologia dos tipos de bens patrimoniais.

O campo 2.3 (Número de registro), segundo a orientação do PDI, deve ser preenchido por uma combinação de letras e números, sendo a primeira parte a identificação da fazenda, a segunda o tipo de bem que se trata (material ou imaterial) e a terceira onde o bem se encontra, conforme o exemplo: FP-A-T1 (FAZENDA PINHAL-ARQUITETÔNICO-TULHA 1). Como a intenção é numerar o registro na base, uma sequência numérica pré-programada na base de dados resolve o problema, tal qual - MARC 21 faz no campo 001 (Número de controle), visto que para a identificação da fazenda são preenchidos os campos do grupo 1 e para os dados de localização do item em determinada fazenda há o campo 2.6 (Localização física específica).

O preenchimento do campo 2.4 (Título) evidenciou a necessidade de acrescentar no subitem 2.4.1 (Tipo do título) a nomenclatura "Parte", que indica a subdivisão de uma partitura; e destaca-se que o PDI possibilita que este campo seja repetido quando necessário, bem como os demais campos do grupo 2; ademais, não se aplica ao PDI a designação geral do material, presente no campo 245 (Título) do MARC 21.

Os Quadros 3 e 4 tratam de informações acerca da autoria da obra, conforme exposição a seguir:

Quadro 3 - Comparação do grupo 3 do PDI

\begin{tabular}{l|l|l|c}
\hline \multicolumn{1}{c|}{ PADRÃO DE DESCRIÇÃO DE INFORMAÇÃO } & \multicolumn{2}{c}{ MARC 21 } \\
\cline { 1 - 2 } \multicolumn{1}{c|}{ Grupo/ Item / Nome } & \multicolumn{1}{c|}{ Descrição } & Campo & Representação \\
\hline \hline G3 Autor ou responsável & Antonio Carlos Gomes & $\begin{array}{l}\text { Entrada principal - } \\
\text { Nome pessoal }\end{array}$ & $\begin{array}{c}1001 \text { \# \$a Gomes, Antonio Carlos, } \\
\text { \$d 1836-1896. }\end{array}$ \\
\cline { 1 - 2 } G3 Tipo de autoria: & Outras: compositor & & \\
\hline
\end{tabular}

Fonte: Dados da pesquisa.

O Quadro 3 evidencia que enquanto o PDI traz no grupo 3 a indicação de responsabilidade da obra e tipo de autoria, o MARC 21 aponta não apenas a responsabilidade intelectual, como também datas relacionadas. Sugere-se a inclusão dos seguintes tipos de autoria: compositor, arranjador, adaptador e copista.

Quadro 4 - Comparação do grupo 4 do PDI

\begin{tabular}{|c|c|c|c|}
\hline \multicolumn{2}{|c|}{ PADRÃO DE DESCRIÇÃO DE INFORMAÇÃO } & \multicolumn{2}{|c|}{ MARC 21} \\
\hline Grupo/ Item / Nome & Descrição & Campo & Representação \\
\hline G4 Sobrenome & Gomes, & \multirow{6}{*}{\multicolumn{2}{|c|}{ Informações constantes no campo 100.}} \\
\hline G4 Nome & Antonio Carlos, & & \\
\hline G4 Pseudônimo ou codinome & Carlos Gomes & & \\
\hline G4 Função & Outras: & & \\
\hline G4 Data de nascimento & 1836 & & \\
\hline G4 Data de óbito & 1896 & & \\
\hline
\end{tabular}

Fonte: Dados da pesquisa.

O grupo 4 do PDI (Quadro 4) trata de detalhes sobre a responsabilidade da obra, e dado o tipo de informação, sugere-se a mescla dos grupos 3 (Autoria) e 4 (Cadastro de autoria). Caso a obra 
possua mais de autor, é necessário preencher no MARC 21 o campo 700, de entrada secundária para nome pessoal, enquanto o PDI permite repetir o campo de autoria, considerado satisfatório.

Quadro 5 - Comparação do grupo 5 do PDI

\begin{tabular}{|c|c|c|c|}
\hline \multicolumn{2}{|c|}{ PADRÃO DE DESCRIÇÃO DE INFORMAÇÃO } & \multicolumn{2}{|r|}{ MARC 21} \\
\hline Grupo/ Item / Nome & Descrição & Campo & Representação \\
\hline G5 Local & New York & \multirow{3}{*}{ Imprenta } & \multirow{3}{*}{$\begin{array}{l}260 \text { \# \# \$a New York: } \\
\text { \$b The Autopiano Company, } \\
\text { \$c [1904]. }\end{array}$} \\
\hline G5 Ano & [1904] & & \\
\hline G5 Outras responsabilidades & The Autopiano Company & & \\
\hline
\end{tabular}

Fonte: Dados da pesquisa.

A análise comparativa do grupo 5 do PDI e do campo 260 (Imprenta) do MARC 21 (Quadro 5) evidenciou que o PDI é capaz de representar a informação de modo satisfatório, e ao contrário do MARC 21 que possui o campo 250 para indicação de edição, o PDI incorpora a edição neste grupo. O Grupo 5 (Produção) é considerado satisfatório, pois permite que sejam descritos todos os detalhes sobre a publicação e distribuição do item, tais como: local de publicação, identificação do editor ou publicador, data da publicação, distribuição etc. Sugere-se que o campo "Outras responsabilidades" seja renomeado para "Nome do editor, publicador etc.", assim como o MARC 21 utiliza, uma vez que o PDI indica que neste campo são indicados os envolvidos com a produção do bem, evitando assim erros ou dúvidas quanto à função do campo.

Quadro 6 - Comparação do grupo 6 do PDI

\begin{tabular}{l|l|c|c}
\hline \multicolumn{2}{c|}{ PADRÃO DE DESCRIÇÃO DE INFORMAÇÃO } & \multicolumn{1}{c}{ MARC 21 } \\
\hline \multicolumn{1}{c|}{ Grupo/ Item / Nome } & \multicolumn{1}{c}{ Descrição } & Campo & Representação \\
\hline \hline $\begin{array}{l}\text { G6 6.1 Características físicas } \\
\text { e técnicas executivas }\end{array}$ & 1 partitura & Descrição física & 300 \# \# \$a 1 partitura. \\
\hline G6 6.3 Conteúdo & $\begin{array}{l}\text { Música escrita em } \\
\text { homenagem... }\end{array}$ & Nota de resumo & $\begin{array}{c}520 \text { \# \# \$a Música escrita em } \\
\text { homenagem... }\end{array}$ \\
\hline
\end{tabular}

Fonte: Dados da pesquisa.

Acerca das informações expostas no Quadro 6, é recomendado utilizar no campo 6.1 (Características físicas e técnicas executivas) do PDI a divisão adotada pelo MARC 21 , por ser mais clara e objetiva tanto para aquele que descreve 0 item quanto para quem pesquisa pelo item na base. Para música escrita, as opções de descrição seriam: quantidade de folhas, quantidade de partes, número da parte, ilustrações, presença de material adicional (fita, CD, disco). Já o campo 6.1.4 (Notas) destina-se a informações gerais, especiais, de conteúdo e outras observações, considerado satisfatório.

O campo 6.3 (Conteúdo) descreve o bem material conforme o âmbito e o conteúdo do item, estilo, resumo do item, descrição física, análise estilística e iconográfica e época; sugere-se que este campo trate apenas do resumo do item, pois a descrição física do item consta no campo 6.1. (Características físicas e técnicas executivas), e as demais informações podem ser realocadas nos campos dos grupos 7 (Audiovisual), 8 (Diagnóstico e Intervenção) e 11 (Assunto e descritores). 
As partituras podem trazer informações como anotações realizadas pelo compositor/ arranjador, instrumentação necessária para a execução da peça musical, dentre outras, e para este caso recomenda-se o uso do item 6.1.4 (Notas); o item 6.3 (Conteúdo) pode ser utilizado para resumo da obra, neste caso constariam informações sobre o contexto da composição da obra. Aconselha-se ainda a criação de um campo para indicação de série, representado pelo campo 490 do MARC 21.

Quadro 7 - Comparação do grupo 7 do PDI

\begin{tabular}{l|l|l|c}
\hline \multicolumn{2}{c|}{ PADRÃO DE DESCRIÇÃO DE INFORMAÇÃO } & \multicolumn{1}{c}{ MARC 21 } \\
\hline \multicolumn{1}{c|}{ Grupo/ Item / Nome } & \multicolumn{1}{c}{ Descrição } & Campo & Representação \\
\hline \hline $\begin{array}{l}\text { O grupo 7 (Audiovisual) utiliza imagens do item para } \\
\text { ilustrar o registro. }\end{array}$ & $\begin{array}{l}\text { Localização e } \\
\text { acesso } \\
\text { eletrônico }\end{array}$ & $\begin{array}{c}85640 \text { \$u www.mvr.com.br/ilguarany.jpg } \\
\text { \$y Il Guarany }\end{array}$ \\
\hline G7 Título & Il Guarany: overture & Título principal & $\begin{array}{c}24510 \text { \$a Il Guarany: } \\
\text { \$b overture (sinfonia) / }\end{array}$ \\
\hline G7 Tipo & Imagem & - & - \\
\hline
\end{tabular}

Fonte: Dados da pesquisa.

O campo 7 (Audiovisual) do PDI (Quadro 7) é destinado para apresentação de imagens do bem patrimonial coletado durante 0 inventário; no caso de partituras, deve-se tirar uma foto da página de rosto e demais fontes relacionadas ao material; os demais campos pertencentes a este grupo são considerados desnecessários, por repetirem dados anteriormente descritos, como o título, tipo e descrição.

Quadro 8 - Comparação do grupo 8 do PDI

\begin{tabular}{l|l|l|l}
\hline \multicolumn{1}{c|}{ PADRÃO DE DESCRIÇãO DE INFORMAÇÃO } & \multicolumn{1}{c}{ MARC 21 } \\
\hline \multicolumn{1}{c|}{ Grupo/ Item / Nome } & \multicolumn{1}{c}{ Descrição } & \multicolumn{1}{c}{ Campo } & - \\
\hline \hline $\begin{array}{l}\text { G8 8.1 Estado de } \\
\text { conservação e preservação }\end{array}$ & Bom & - & - \\
\hline $\begin{array}{l}\text { G8 8.2 Notas estado de } \\
\text { conservação }\end{array}$ & $\begin{array}{l}\text { Partitura em bom estado de } \\
\text { conservação }\end{array}$ & - & - \\
\hline G8 8.3 Intervenção no bem & Não & - & - \\
\hline
\end{tabular}

Fonte: Dados da pesquisa.

Os campos descritivos do grupo 8 do PDI (Quadro 8), em comparação ao MARC 21 foram considerados satisfatórios.

Quadro 9 - Comparação do grupo 9 do PDI

\begin{tabular}{l|l|l|l}
\hline \multicolumn{2}{c|}{ PADRÃO DE DESCRIÇÃO DE INFORMAÇÃO } & \multicolumn{1}{c}{ MARC 21 } \\
\hline \multicolumn{1}{c|}{ Grupo/ Item / Nome } & \multicolumn{1}{c}{ Descrição } \\
\hline \hline G9 Disponibilidade & Exposição permanente & - & \multicolumn{1}{c}{ Campo } \\
\hline G9 Condições de acesso & Não circula & $\begin{array}{l}\text { Nota de } \\
\text { restrição de } \\
\text { acesso }\end{array}$ & $\begin{array}{l}506 \text { \# \# \$a Acesso restrito; } \\
\text { \$c Necessário autorização prévia. }\end{array}$ \\
\hline G9 Condições de reprodução & Não & - & - \\
\hline
\end{tabular}

Fonte: Dados da pesquisa.

O grupo 9 do PDI, exposto no Quadro 9, após comparação com o MARC 21 não evidenciou necessidade de intervenção.

Quadro 10 - Comparação do grupo 10 do PDI 


\begin{tabular}{l|l|l|l}
\hline \multicolumn{1}{c|}{ Grupo/ Item / Nome } & \multicolumn{1}{c|}{ Descrição } & \multicolumn{1}{c}{ Campo } & \multicolumn{1}{c}{ Representação } \\
\hline \hline G10 Tipo de aquisição & Compra & * Ver: Nota da fonte imediata de aquisição \\
\hline $\begin{array}{l}\text { G10 Valor venal da época da } \\
\text { transacão }\end{array}$ & Não consta & Preço & $\begin{array}{l}365 \text { \# \# \$a 01 } \\
\text { \$b Valor }\end{array}$ \\
\hline G10 Data da aquisição & Não consta & $\begin{array}{l}\text { Nota da fonte } \\
\text { imediata de }\end{array}$ & $\begin{array}{l}5411 \text { \# \$c Forma de aquisição (compra, } \\
\text { doacão. permuta): \$d Data da aquisicão. }\end{array}$ \\
\hline
\end{tabular}

Fonte: Dados da pesquisa.

O Quadro 10 demonstra que o grupo 10 (Histórico da procedência) do PDI, ao ser comparado com a catalogação realizada com o MARC 21, cumpre a função de informar ao usuário dados sobre a aquisição do item.

Quadro 11 - Comparação do grupo 11 do PDI

\begin{tabular}{|c|c|c|c|}
\hline \multicolumn{2}{|c|}{ PADRÃO DE DESCRIÇÃO DE INFORMAÇÃO } & \multicolumn{2}{|r|}{ MARC 21} \\
\hline Grupo/ Item / Nome & Descrição & Campo & Representação \\
\hline G11 Assunto & Partitura para pianola & - & \\
\hline G11 Descritores & Partitura para piano. & $\begin{array}{l}\text { Assunto - Nome } \\
\text { geográfico }\end{array}$ & $\begin{array}{c}6504 \text { \# \$a Música para piano - } \\
\text { \$x Partituras. }\end{array}$ \\
\hline
\end{tabular}

Fonte: Dados da pesquisa.

A sugestão, após a análise do Quadro 11, é a substituição no grupo 11 do PDI (Assunto e Descritores) do termo assunto principal ao invés de assunto, e substituir o termo descritores por termos relacionados, para que os termos do tesauro do projeto sejam aqui abrigados.

Quadro 12 - Comparação do grupo 12 do PDI

\begin{tabular}{c|c|l|c}
\hline \multicolumn{2}{c|}{ PADRÃO DE DESCRIÇ̃̃O DE INFORMAÇÃO } & \multicolumn{2}{c}{ MARC 21 } \\
\hline Grupo/ Item / Nome & Descrição & Campo & Representação \\
\hline \hline G12 Fonte de informação & Próprio item & $\begin{array}{l}\text { Fonte da } \\
\text { catalogação }\end{array}$ & $\begin{array}{c}\text { 040 \# \# \$a Código da agência catalogadora } \\
\text { \$b Idioma da catalogação }\end{array}$ \\
\hline
\end{tabular}

Fonte: Dados da pesquisa.

Acerca do Quadro 12, constata-se que o PDI considera relevante indicar a procedência dos dados, ao solicitar do catalogador a informação da fonte de informação, como o próprio item ou materiais que dele fazem parte, tal como o MARC 21 considera.

Quadro 13 - Comparação do grupo 13 do PDI

\begin{tabular}{l|c|c|c}
\hline \multicolumn{2}{c|}{ PADRÃO DE DESCRIÇÃO DE INFORMAÇÃO } & \multicolumn{2}{c}{ MARC 21 } \\
\hline \multicolumn{1}{c|}{ Grupo/ Item / Nome } & Descrição & Campo & Representação \\
\hline \hline G13 Nome & Milene Rosa de Almeida & Catalogador & $\begin{array}{c}\text { CAT \$a MILENE } \\
\text { \$c 20130510 }\end{array}$ \\
\hline G13 Data & $10 / 05 / 2013$ & $\begin{array}{l}\text { Data e hora } \\
\text { da última } \\
\text { atualização }\end{array}$ & 005 Gerado automaticamente pelo sistema \\
\hline
\end{tabular}

Fonte: Dados da pesquisa.

Por fim, foram analisados os dados relacionados à identificação do catalogador e criação do registro, conforme expresso pelo quadro 13 , os quais são plenamente atendidos pelo PDI.

\section{Considerações finais}

A colonização do interior paulista, entre os séculos XVIII e XIX e o consequente enriquecimento da classe social produtora de cana de açúcar 
e café resultaram no desenvolvimento de uma região que outrora era predominada pelas matas. As fazendas, muito mais que um símbolo de poder de uma época, permitem que as novas gerações conheçam o processo de colonização desta região do País sob diversos aspectos: histórico, artístico, arquitetônico, cultural, dentre outros. Como consequência, cada fazenda traz em si o peso da responsabilidade da preservação, tanto de seus bens móveis como das memórias que dela fazem parte.

O desafio de preservar o patrimônio histórico rural culminou no desenvolvimento de projetos de políticas públicas anteriormente mencionados, envolvendo pesquisadores de diversas áreas, os quais analisaram o ambiente das fazendas históricas sob diferentes aspectos. É importante ressaltar que a documentação existente nessas fazendas desempenha um papel importante nas atividades cotidianas, visto que a conjunção do presente e do passado possibilita a compreensão do processo de formação da atual sociedade.

No presente estudo, o MARC 21 foi utilizado como um instrumento de apoio no aperfeiçoamento do Padrão de Descrição de Informação, pois associado ao código AACR2, permite representar um documento de modo completo e padronizado, visando sua fácil recuperação pelo usuário.

O MARC 21 apresenta inúmeras vantagens, como a possibilidade de repetir boa parte de seus campos e subcampos, detalhando minuciosamente os pormenores existentes no material e a objetividade em seu preenchimento, permitindo identificar e sugerir modificações no Padrão de Descrição de Informação. O PDI foi elaborado com o intuito de permitir que qualquer bem patrimonial, seja ele material ou imaterial, bibliográfico, arquitetônico e outros seja descrito de modo padronizado, assim como o MARC 21 o é.

Com base nas análises realizadas utilizando partitura de pianola, considera-se que a representação documental através do PDI atendeu positivamente às expectativas, visto que as intervenções apontadas são consideradas pequenas, dada a quantidade de campos e a variedade de materiais que podem ser descritos utilizando o padrão. Aponta-se a necessidade de realização de estudos voltados à normalização da pontuação, abreviações e demais simbologias.

Esse é um dos primeiros estudos sobre as minúcias dos campos do PDI e ressalta-se que novas alterações podem vir a ocorrer, a fim de aperfeiçoar o mesmo, reafirmando o papel dos códigos e padrões de catalogação de cumprirem o princípio maior da catalogação, segundo a International Federation of Library Associations and Institutions (IFLA): atender a conveniência dos utilizadores do catálogo, ou seja, os usuários.

\section{Referências}

ALVES, R. C. V. Metadados como elementos do processo de catalogação. 2010. Dissertação (Mestrado em Ciência da Informação) - Departamento de Ciência da Informação, Universidade Estadual Paulista, Marília, 2010. 
BARBOSA, E. M. de S.; EDUVIRGES, J. R. O formato MARC 21: principais vantagens para bibliotecários, bibliotecas e usuários para a recuperação da informação. In: ENCONTRO NACIONAL DE ESTUDANTES DE BIBLIOTECONOMIA, DOCUMENTAÇÃO, GESTÃO E CIÊNCIA DA INFORMAÇÃO, 33., 2010, João Pessoa. Anais [...]. João Pessoa: UFPb, 2010. Disponível em: http://dci.ccsa.ufpb.br/enebd/index.php/enebd/article/viewFile/14/18.

Acesso em: 20 mar. 2016.

COSTA, L. S. F.; SCARPELINE, R.; NAKAGAWA, E. Y. Uma proposta teórico-metodológica de inventário patrimonial no contexto das fazendas históricas paulista. In: SEMINÁRIO DE PATRIMÔNIO AGROINDUSTRIAL: lugares de memória, 2., 2010, São Carlos. Anais [...]. São Carlos: USP, 2010. p. 1-12.

FERREIRA, M. M. (Trad. e Adap.). MARC 21: formato condensado para dados bibliográficos. Marília: Editora Unesp, 2002. v. 1.

MEMÓRIA Virtual de São Carlos. São Carlos, SP: Instituto de Ciências Matemáticas e de Computação - ICMC/USP, 2004-2008. (Projeto aprovado no programa de políticas públicas da FAPESP e coordenado pelo Prof. Dr. José Carlos Maldonado).

MEY, E. S. A.; SILVEIRA, N. C. Catalogação no plural. Brasília: Briquet de Lemos, 2009.

NAKAGAWA, E. Y.; COSTA, L. S. F.; SCARPELINE, R. Fazendas históricas paulistas dos séculos XVIII e XIX: premissas teóricas e metodológicas para inventariar bens patrimoniais. RESGATE - Revista Interdisciplinar de Cultura, v. 18, n. 20, p. 37-53, jul./dez. 2010. Disponível em: http://www.cmu.unicamp.br/seer/index.php/resgate/article/view/305/301 . Acesso em: 25 mar. 2016.

NAKAGAWA, E. Y.; CRISTIANINI, G.M.S.; MORAES, J.S. Democratização de acervos especiais: o modelo do projeto "Memória Virtual de São Carlos". In: SEMINÁRIO NACIONAL DE BIBLIOTECAS UNIVERSITÁRIAS, 14., 2006, Salvador. Anais [...]. Porto Alegre: SBC, 2006. p. 1-10. 